\title{
Characterization of Creaming Precipitate of Tea Catechins and Caffeine in Aqueous Solution
}

\author{
Takashi Sato, ${ }^{a}$ Yoshifumi Kinoshita,${ }^{a}$ Hiroyuki Tsutsumi,${ }^{a}$ Hideji Yamamoto, ${ }^{b}$ and \\ Takashi Ishizu*,a \\ ${ }^{a}$ Faculty of Pharmacy and Pharmaceutical Sciences, Fukuyama University; and ${ }^{b}$ Department of Applied Biological \\ Science, Faculty of Engineering, Fukuyama University; Sanzo Gakuen-cho 1, Fukuyama, Hiroshima 729-0292, \\ Japan. Received May 10, 2012; accepted June 19, 2012
}

The content of a crude precipitate formed by creaming, which was made from a catechin mixture and caffeine, was investigated by an integral volume of $\mathbf{H}-2$ proton signals of tea catechins in the ${ }^{1} \mathrm{H}-\mathrm{NMR}$ spectrum. Gallated catechins formed a crude precipitate more predominantly than non-gallated catechins. The 2,3-cis-non-gallated catechin (-)-epicatechin (EC) formed a $1: 1$ complex with caffeine, and 2,3-cis-gallated catechin (-)-epicatechin gallate (ECg) formed a 2:4 complex with caffeine. The $\pi-\pi$ complexation site of EC with caffeine was only the A ring, whereas that of $\mathbf{E C g}$ included all aromatic rings, $A, B$, and $B^{\prime}$. It was thought that the hydrophobicity of the $2: 4$ complex of ECg and caffeine was stronger than that of the $1: 1$ complex of EC and caffeine, with the result that the 2:4 complex of ECg and caffeine precipitated by creaming more predominantly than the $1: 1$ complex of EC and caffeine in aqueous solution.

Key words creaming down; (-)-epicatechin; (-)-epicatechin-3-O-gallate; caffeine; $\pi-\pi$ interaction; X-ray crystallographic analysis

Tea has been consumed in many countries throughout the world since ancient times for taste and to maintain and improve health. It is well known that tea protects against lifestyle-related diseases such as cancer, high blood pressure, diabetes, obesity, and arteriosclerosis. ${ }^{1}$ Tea is made from leaves of the tea plant, Camellia sinensis, Theaceae, which includes caffeine, catechins, tannins, vitamins, theanine, etc. Catechins are a group of polyphenols that show various physiologically modulating effects, such as anti-carcinogenic, anti-metastatic, and anti-oxidative. ${ }^{2-7)}$ The eight major tea catechins are classified into four categories by the existence of a galloyl group on the oxygen atom at the $\mathrm{C}-3$ position and the relative stereochemistry between the $\mathrm{C}-2$ and $\mathrm{C}-3$ positions: 2,3-cis-gallated, 2,3-trans-gallated, 2,3-cis-non-gallated, and 2,3-trans-non-gallated ${ }^{8)}$ (Fig. 1). Generally, gallated catechins show higher activities than non-gallated catechins. ${ }^{9-12)}$

When a hot tea beverage cools down, it becomes turbid and brown-white particles settle out. This phenomenon is called "creaming" or "creaming down (reaction)." Since creaming is a trigger to deform the original appearance and color of tea, it is one of the most serious problems in making a tea beverage. Caffeine has been suggested to form a cream with tea polyphenols such as catechins, theaflavins and thearubigins. ${ }^{13)}$ Previously, Maruyama et al. reported that all the main signals were assigned to catechins such as (-)-epigallocatechin gallate $(\mathrm{EGCg})$ and $(-)$-epicatechin gallate $(\mathrm{ECg})$ and caffeine in

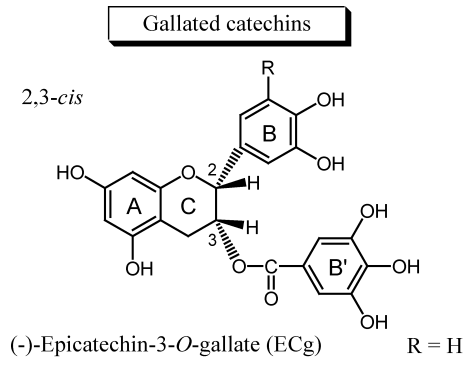

(-)-Epigallocatechin-3-O-gallate (EGCg) $\mathrm{R}=\mathrm{OH}$

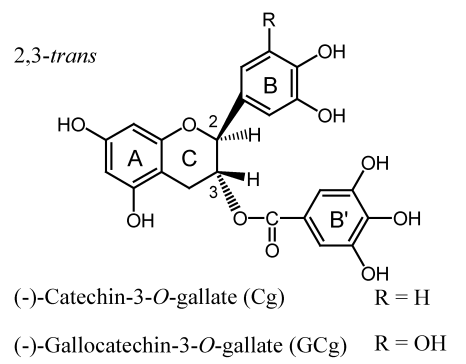

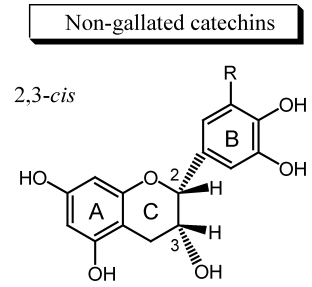

(-)-Epicatechin (EC) $\quad \mathrm{R}=\mathrm{H}$

(-)-Epigallocatechin (EGC) $\quad \mathrm{R}=\mathrm{OH}$

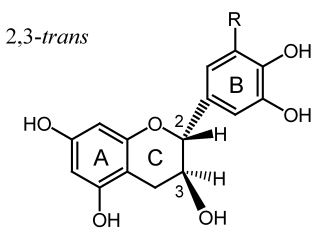

(+)-Catechin (CA) $\quad \mathrm{R}=\mathrm{H}$

$(+)$-Gallocatechin $(\mathrm{GC}) \quad \mathrm{R}=\mathrm{OH}$

Fig. 1. The Eight Major Tea Catechins and Caffeine 


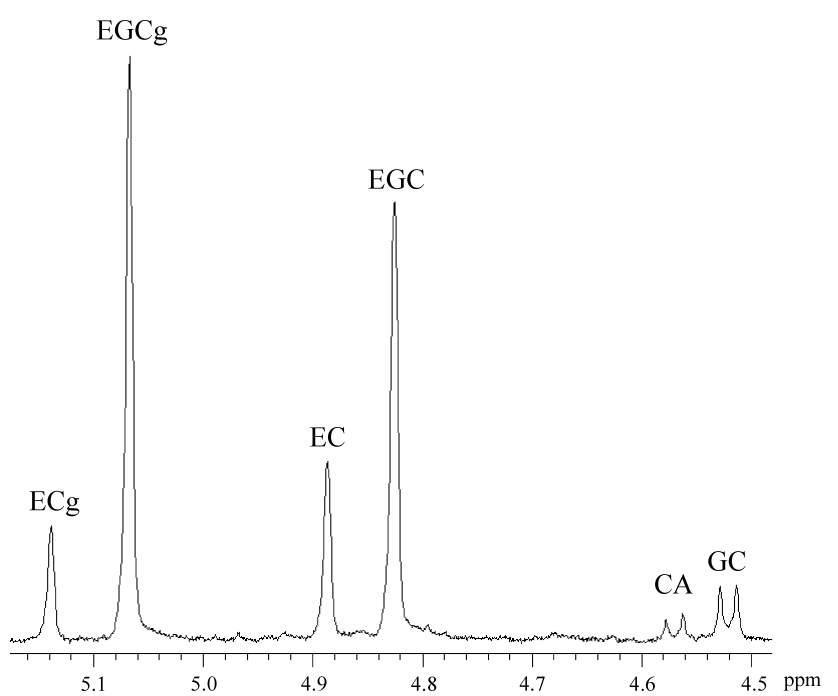

Fig. 2. The Methine Proton H-2 Signal of Each Catechin of the Catechin Mixture in ${ }^{1} \mathrm{H}-\mathrm{NMR}$ Spectrum

the ${ }^{13} \mathrm{C}$-NMR spectrum of a hot water solution of a crude precipitate formed by the creaming of a tea infusion. ${ }^{14)}$ Creaming down eventually occurs, when an aqueous caffeine solution is poured into an aqueous EGCg solution ${ }^{14)}$; however, creaming down in tea beverages has not been chemically elucidated sufficiently. In this paper, we describe a new method for quantitative analysis of a crude precipitate of creaming made from a catechin mixture and caffeine using an integral volume of the proton signal of the ${ }^{1} \mathrm{H}-\mathrm{NMR}$ spectrum. The catechin mixture is a fraction of extracted catechins included in green tea. The stereochemical structure of the complexes of tea catechins (-)-epicatechin (EC), ECg and caffeine was determined by $\mathrm{X}$-ray crystallography, and the molecular interactions between the tea catechins and caffeine were investigated. ${ }^{15}$

\section{Results and Discussion}

Analysis of the Catechin Mixture Using ${ }^{1} \mathrm{H}-\mathrm{NMR}$ Spectra First the content of tea catechins containing in the catechin mixture was measured by the integral volume of the proton signal of the ${ }^{1} \mathrm{H}-\mathrm{NMR}$ spectrum. No overlap of the methine proton $\mathrm{H}-2$ signal of each catechin in acetone- $d_{6}$ was observed in the ${ }^{1} \mathrm{H}-\mathrm{NMR}$ spectrum. ${ }^{16}$ ) The integral volume of the H-2 proton signal of each catechin contained in the catechin mixture was then measured, using the methyl proton signal (singlet) of Boc-glycine as an internal standard (Fig. 2). The content of the catechin mixture is shown in Table 1, indicating that it included a large amount of 2,3-cis-type catechins, such as EGCg, ECg, and EC; thus, a simple and easy method for quantitative analysis of a sample containing many kinds of catechin using the ${ }^{1} \mathrm{H}-\mathrm{NMR}$ spectrum was developed.
The reported content of catechins in green tea was shown also in Table $1{ }^{17)}$

As shown in Fig. 2, the H-2 proton signal of 2,3-cis catechins of EGC, EC, EGCg, and ECg was observed as singletlike, whereas that of 2,3-trans catechins of (+)-gallocatechin (GC) and (+)-catechin (CA) was observed as a doublet in the ${ }^{1} \mathrm{H}-\mathrm{NMR}$ spectrum. Such a difference in coupling patterns resulted from their conformational difference. Judging from the coupling constant $J_{2,3}$ of EGC, EC, EGCg, and ECg being $c a .0 \mathrm{~Hz}$, it was thought that their dihedral angle $\angle \mathrm{H}-2-\mathrm{C}-2-\mathrm{C}-3-\mathrm{H}-3$ was approximately $90^{\circ}$, judging from the Kurplus equation. ${ }^{18)}$ On the other hand, since $J_{2,3}$ of CA and $\mathrm{GC}$ were $7.8 \mathrm{~Hz}$ and $7.4 \mathrm{~Hz}$, respectively, their dihedral angle $\angle \mathrm{H}-2-\mathrm{C}-2-\mathrm{C}-3-\mathrm{H}-3$ was expected to be considerably larger than $\left.90^{\circ} .18,19\right)$

Analysis of the Crude Precipitate Formed by Creaming Using ${ }^{1}$ H-NMR Spectra Equimolar amounts of the catechin mixture and caffeine were dissolved in $\mathrm{D}_{2} \mathrm{O}$ at $90^{\circ} \mathrm{C}$ and left at room temperature for a day. The solution was divided into the supernatant liquid and sticky precipitate, which is a crude precipitate formed by creaming. The content of the supernatant liquid and the sticky precipitate was investigated by similar analytical method using an integral volume of the $\mathrm{H}-2$ proton signal of catechins and the $\mathrm{H}-8$ proton signal of caffeine in the ${ }^{1} \mathrm{H}-\mathrm{NMR}$ spectra. The contents of various tea catechins and caffeine are listed in Table 2.

As shown in Table 2, more than $80 \%$ of gallated catechins were contained in the catechin mixture, EGCg and ECg, and were the present in crude precipitate formed by creaming, and $45.9-64.7 \%$ of non-gallated catechins, EGC, EC, GC, and $\mathrm{CA}$, were present. This finding suggested that the gallated catechins were predominantly responsible for creaming rather than the non-gallated catechins.

To confirm this, the following experiment was performed. A solution of equimolecular amounts of a gallated catechin ECg and non-gallated catechin EC, and twice the molecular amount of caffeine were dissolved in $\mathrm{D}_{2} \mathrm{O}$ at $90^{\circ} \mathrm{C}$ and left at room temperature for a day. The structural difference between $\mathrm{EC}$ and ECg is the presence of a galloyl group on the oxygen atom at the C-3 position or absence; all others are the same and are included in Japanese green tea as the major catechins. The solution was divided into a supernatant liquid and sticky precipitate, which is a crude precipitate formed by creaming. As shown in Table 3, 88.8\% ECg were present in the crude precipitate formed by creaming, whereas $46.4 \%$ EC were present (Table 3); therefore, the finding supported the evidence that gallated catechins were predominantly responsible for creaming rather than non-gallated catechins.

X-Ray Crystallographic Analysis of the Complex of EC, ECg and Caffeine The molecular interactions between tea catechins and caffeine in the crude precipitate formed by

Table 1. The Content of Tea Catechins in the Catechin Mixture

\begin{tabular}{lcccccc}
\hline \hline & EGCg & EGC & EC & ECg & GC & CA \\
\hline Content (mg) & 5.13 & 2.70 & 0.99 & 0.97 & 0.43 & 0.17 \\
$\begin{array}{c}\text { Amount of substance } \\
\text { (mmol) }\end{array}$ & 0.011 & 0.009 & 0.003 & 0.002 & 0.001 & 0.001 \\
$\begin{array}{l}\text { Relative content (\%) } \\
\begin{array}{c}\text { Relative content (\%) of } \\
\text { green tea }\end{array}\end{array}$ & 49.37 & 25.99 & 9.53 & 9.34 & 4.14 & 1.64 \\
\hline
\end{tabular}


creaming were investigated by X-ray crystallographic analysis. Crystals of the complexes of EC, ECg and caffeine were prepared, and X-ray crystallographic analysis of the complexes was performed to determine the crystal stereochemical structures and to elucidate the detailed non-covalent interactions among EC, ECg and caffeine moieties. Furthermore, we investigated differences in the stereochemical structures and noncovalent interactions, whether having a galloyl group or not.

Stereochemical Structure of the 1:1 Complex of EC and Caffeine A solution containing equimolecular amounts of EC and caffeine in water afforded colorless block crystals. A single crystal $(0.50 \times 0.40 \times 0.11 \mathrm{~mm})$ was determined to be a $1: 1$ complex of EC and caffeine by X-ray crystallographic analysis and was monoclinic with space group $C 2$ (No. 5). ${ }^{15)}$ One unit cell dimensions were $a=27.2246(12) \AA$, $b=6.6953(3) \AA$ and $c=17.4322(8) \AA$, respectively. An ORTEP drawing of a unit of the 1:1 complex of EC and caffeine is shown in Fig. 3a. One unit cell contained four units of the $1: 1$ complex of EC and caffeine and eight water molecules as crystal solvent (Fig. 3b).

$\mathrm{EC}$ and ECg molecules have conformational flexibility, including orientation of the linkage between $\mathrm{B}, \mathrm{B}^{\prime}$ and $\mathrm{C}$ rings owing to puckering of the pyran $\mathrm{C}$ ring. The caffeine molecule has a plain and rigid xanthine skeleton. The torsion angles of the EC moiety of the 1:1 complex (Table 4) indicated that the $\mathrm{B}$ ring and 3-OH group of $\mathrm{EC}$ were in equatorial and axial positions with respect to the $\mathrm{C}$ ring of the $\mathrm{EC}$ molecule, respectively.

In the layer structure shown in Fig. 4, units of the $1: 1 \mathrm{com}-$ plex of EC and caffeine were stacked in parallel in the same direction as the $b$-axis. The A ring of EC and the six-membered ring of caffeine appear in turn along the $b$-axis, and the six-membered rings of caffeines were located in almost the middle of the A rings of ECs. The A rings of both upper and lower ECs faced the six-membered ring of caffeine.

In the $1: 1$ complex of EC and caffeine, face-to-face $\pi-\pi$ stacking interactions formed between the A ring of EC and the six-membered ring of caffeine. Also, a $\mathrm{CH}-\pi$ interaction formed between $\mathrm{C}(14)-\mathrm{H}(14)$ of the $\mathrm{B}$ ring and the $\mathrm{B}$ ring (Fig. 4). Two $\mathrm{O}-\mathrm{H} \cdots \mathrm{O}$ intermolecular hydrogen bonds were also observed.

Stereochemical Structure of the 2: 4 Complex of ECg and Caffeine A suspension containing equimolecular amounts of $\mathrm{ECg}$ and caffeine in water afforded colorless block crystals. A single crystal $(0.35 \times 0.25 \times 0.16 \mathrm{~mm})$ was determined to be a 2:4 complex of ECg and caffeine by X-ray crystallographic analysis and was monoclinic with space group $P 2_{1}$ (No. 4). ${ }^{15}$ ) One unit cell dimensions were $a=14.0190(7) \AA, b=8.9403(4) \AA$ and $c=31.4760(15) \AA$, respectively. An ORTEP drawing of a unit cell of the $2: 4$ complex of ECg and caffeine is shown in Fig. 5a. In a unit of the 2:4 complex, the $B$ and $B^{\prime}$ rings of one $\mathrm{ECg}(\mathrm{ECg} \mathrm{A})$ faced the caffeines and the $\mathrm{A}$ and $\mathrm{B}^{\prime}$ rings of the other ECg (ECg B) faced the caffeines. One unit cell contained two units of the 2:4 complex of ECg and caffeine and twelve water molecules as a crystal solvent (Fig. 5b).

The torsion angles of the ECg moieties (ECg A and B) of the 2:4 complex (Table 4) indicated that $\mathrm{B}$ rings of $\mathrm{ECg} \mathrm{A}$ and $\mathrm{ECg} \mathrm{B}$ were both in equatorial positions and $\mathrm{B}^{\prime}$ rings of $\mathrm{ECg} \mathrm{A}$ and $\mathrm{ECg} \mathrm{B}$ were both in axial positions with respect to the $\mathrm{C}$ rings of $\mathrm{ECg}$ molecules.

In the layer structure shown in Fig. 6, units of the 2:4 complex of ECg and caffeine stacked in parallel in the same direction as the $a$-axis. The $\mathrm{B}^{\prime}$ ring of $\mathrm{ECg}$ and caffeine appear in turn along the $a$-axis, and the caffeines were located in almost the middle of the two $\mathrm{B}^{\prime}$ rings of ECgs. Furthermore, the A and $\mathrm{B}$ rings of $\mathrm{ECg}$ faced the caffeines.

Table 2. The Content of Tea Catechins and Caffeine in the Supernatant Liquid and the Sticky Precipitate Made from Catechin Mixture and Caffeine

\begin{tabular}{|c|c|c|c|c|c|c|c|c|}
\hline & & EGCg & EGC & $\mathrm{EC}$ & $\mathrm{ECg}$ & GC & $\mathrm{CA}$ & Caffeine \\
\hline \multirow[t]{2}{*}{ Sample } & Content (mg) & 5.13 & 2.70 & 0.99 & 0.97 & 0.43 & 0.17 & 5.36 \\
\hline & $\begin{array}{l}\text { Amount of substance } \\
\quad(\mathrm{mmol})\end{array}$ & 0.0112 & 0.0088 & 0.0034 & 0.0022 & 0.0014 & 0.0006 & 0.0276 \\
\hline \multirow[t]{3}{*}{ Sticky precipitate } & Content (mg) & 4.22 & 1.24 & 0.53 & 0.81 & 0.24 & 0.11 & 4.46 \\
\hline & $\begin{array}{l}\text { Amount of substance } \\
(\mathrm{mmol})\end{array}$ & 0.0092 & 0.0040 & 0.0018 & 0.0018 & 0.0008 & 0.0004 & 0.0230 \\
\hline & Relative content (\%) & 82.3 & 45.9 & 53.5 & 83.5 & 55.8 & 64.7 & 83.2 \\
\hline \multirow[t]{3}{*}{ Supernatant liquid } & Content (mg) & 0.88 & 1.46 & 0.45 & 0.13 & 0.19 & 0.06 & 0.90 \\
\hline & $\begin{array}{l}\text { Amount of substance } \\
\text { (mmol) }\end{array}$ & 0.0019 & 0.0048 & 0.0016 & 0.0003 & 0.0006 & 0.0002 & 0.0046 \\
\hline & Relative content $(\%)$ & 17.2 & 54.1 & 45.5 & 13.4 & 44.2 & 35.3 & 16.8 \\
\hline
\end{tabular}

Table 3. The Content of ECg, EC and Caffeine in the Supernatant Liquid and the Sticky Precipitate Made from ECg, EC and Caffeine

\begin{tabular}{llccc}
\hline \hline & & ECg & EC & Caffeine \\
\hline Sample & Content (mg) & 4.42 & 2.90 & 3.88 \\
& Amount of substance (mmol) & 0.01 & 0.01 & 0.02 \\
Sticky precipitate & Content (mg) & 3.93 & 1.35 & 3.12 \\
& Amount of substance (mmol) & 0.0089 & 0.0046 & 0.0161 \\
Supernatant liquid & Relative content (\%) & 88.8 & 46.4 & 0.5 \\
& Content (mg) & 0.49 & 1.55 & 0.76 \\
& Amount of substance (mmol) & 0.0011 & 0.054 & 0.0039 \\
\hline
\end{tabular}


(a)

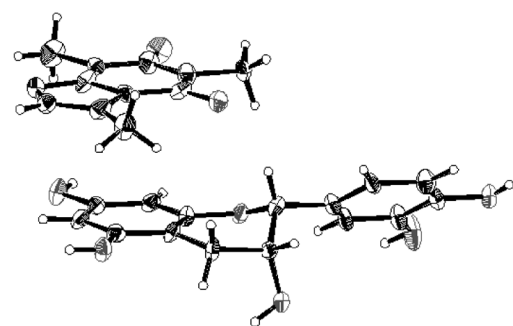

(b)

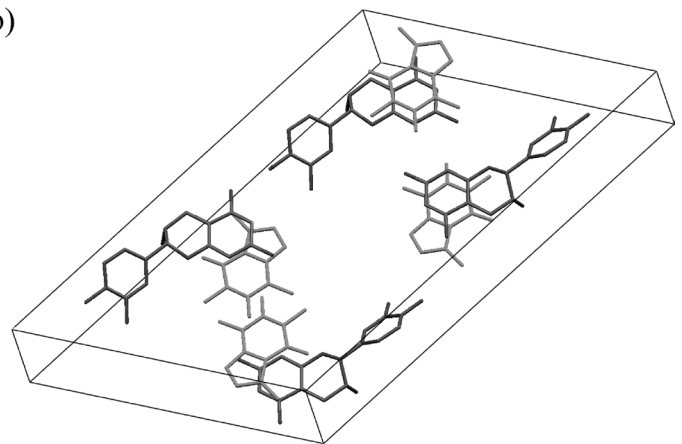

Fig. 3. 1:1 Complex of EC and Caffeine (a) ORTEP Drawing with Thermal Ellipsoids at 30\% Probability Level (b) One Unit Cell Crystal solvent and hydrogen atoms are omitted for clarity.

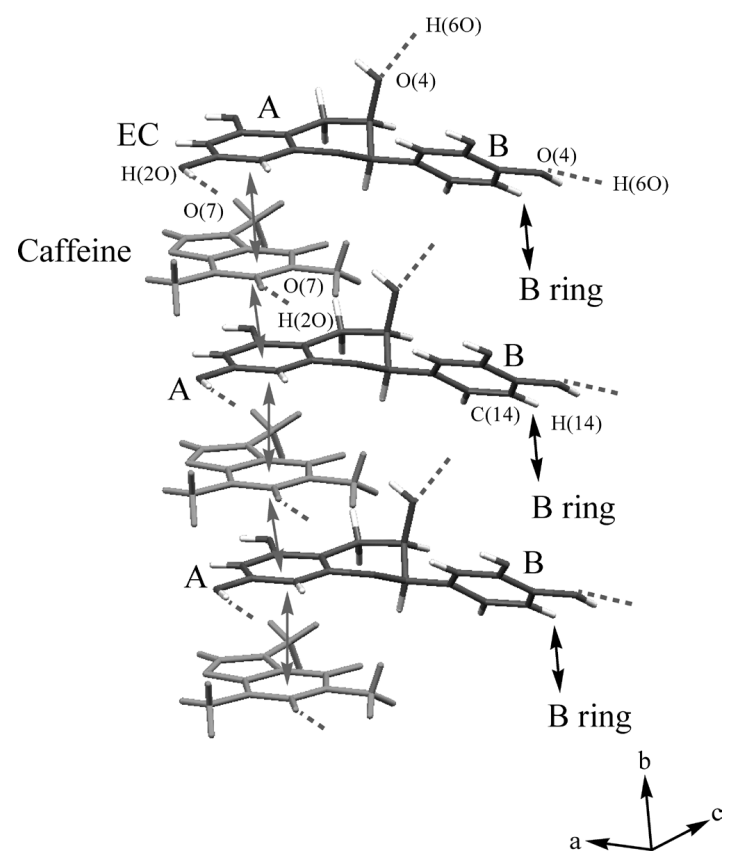

Fig. 4. Layer Structure and Molecular Interactions of $1: 1$ Complex of $\mathrm{EC}$ and Caffeine

Gray and black both arrows and gray dotted lines indicate face-to-face $\pi-\pi$ interactions, $\mathrm{CH}-\pi$ interactions and $\mathrm{O}-\mathrm{H} \cdots \mathrm{O}$ hydrogen bonds, respectively.

In the 2:4 complex of ECg and caffeine, face-to-face and offset $\pi-\pi$ stacking interactions formed between the $\mathrm{B}^{\prime}$ ring of ECg and caffeine (Fig. 6). Also, face-to-face $\pi-\pi$ stacking interactions formed between the A ring of ECg and caffeine, and between the $\mathrm{B}$ ring of $\mathrm{ECg}$ and caffeine. $\mathrm{CH}-\pi$ interactions observed between the methyl group of $\mathrm{N}-1 \mathrm{CH}_{3}$ of caffeine and the A ring of $\mathrm{ECg}$, and methyl group of $\mathrm{N}-7 \mathrm{CH}_{3}$ of caffeine and the $\mathrm{B}$ ring of ECg. Furthermore, three $\mathrm{O}-\mathrm{H} \cdots \mathrm{O}$ and one $\mathrm{O}-\mathrm{H} \cdots \mathrm{N}$ intermolecular hydrogen bonds were formed between ECgs and caffeine moieties.

\section{Conclusion}

Quantitative analysis of a crude precipitate of the creaming from a catechin mixture and caffeine suggested that gallated catechins were predominantly responsible for creaming rather than non-gallated catechins.

X-Ray crystallographic analysis showed that the 2,3-cis-non-gallated catechin (-)-epicatechin (EC) formed a 1:1 complex with caffeine, and 2,3-cis-gallated catechin (-)-epicatechin gallate (ECg) formed a 2:4 complex with caffeine. The molecular interactions among EC, ECg and caffeine in $1: 1$ and $2: 4$ complexes were investigated. The $1: 1$ and $2: 4$ complexes were thought to be formed with the cooperative effect of three (face-to-face $\pi-\pi$ and $\mathrm{CH}-\pi$ interactions and intermolecular hydrogen bonds) and four (face-to-face and offset $\pi-\pi$ stacking interactions, $\mathrm{CH}-\pi$ interaction and intermolecular hydrogen bonds) non-covalent interactions, respectively.

Upon forming $1: 1$ and $2: 4$ complexes, $\pi-\pi$ stacking interactions are thought to play an important role in binding EC and ECg with caffeine. The $\pi-\pi$ complexation site of the non-galloylated catechin EC with caffeine was only the A ring, whereas that of the galloylated catechin ECg was all aromatic rings, A, B, and B'. Haslam insisted that the hydrophobic contribution was probably the most important single factor influencing caffeine-polyphenol interactions in aqueous media. ${ }^{20)}$ It was thought that the hydrophobic effect in the 2:4 complex of ECg and caffeine by $\pi-\pi$ stacking interactions was stronger than that of the $1: 1$ complex of EC and caffeine, with the result that the $2: 4$ complex of the gallated catechin $\mathrm{ECg}$ and caffeine precipitated as an crude precipitate formed by creaming more predominantly than the $1: 1$ complex of the non-gallated catechin EC and caffeine.

\section{Experimental}

Materials Catechin mixture, EC and ECg were purchased from Nagara Science Co., Ltd. Caffeine was purchased from Sigma-Aldrich Co. EC, ECg, and caffeine were used without further purification.

NMR Experiments ${ }^{1} \mathrm{H}-\mathrm{NMR}$ spectra were recorded at $35^{\circ} \mathrm{C}$ on a JEOL JMN-LA500 (Tokyo, Japan) operating at $500 \mathrm{MHz}$, using a $5 \mathrm{~mm} \phi$ sample tube. $\mathrm{D}_{2} \mathrm{O}$ and acetone- $d_{6}$ were used as a solvent ( 99.9 atom\% D; Aldrich Chemical Company, Inc.). Chemical shift values are expressed in ppm downfield using sodium 2,2-dimethyl-2-silapentane-5-sulfonate (DSS), tetramethyl silane (TMS) as an internal standard.

Preparation and Analysis of a Sticky Precipitate Made from Catechin Mixture and Caffeine The catechin mixture $\left(15.00 \mathrm{mg}, 2.76 \times 10^{-2} \mathrm{mmol}\right)$ and caffeine $(5.36 \mathrm{mg}$, $\left.2.76 \times 10^{-2} \mathrm{mmol}\right)$ were dissolved in $\mathrm{D}_{2} \mathrm{O}(100 \mu \mathrm{L})$ at $90^{\circ} \mathrm{C}$ and left at room temperature for a day to obtain a supernatant liquid and a sticky precipitate, which were evaporated under reduced pressure to give residues. The residues were dissolved into $\mathrm{D}_{2} \mathrm{O}(550 \mu \mathrm{L})$ containing DSS $\left(9.82 \mathrm{mg}, 4.50 \times 10^{-2} \mathrm{mmol}\right)$. The contents of the resulting $\mathrm{D}_{2} \mathrm{O}$ solutions were measured using an integral volume of the $\mathrm{H}-2$ proton signal of catechins 
Table 4. Torsion Angles of EC and ECg Moieties in Complex EC and ECg and Caffeine

\begin{tabular}{lll}
\hline \hline & $1: 1$ Complex of EC and caffeine & \multicolumn{2}{c}{$2: 4$ Complex of ECg and caffeine } \\
\cline { 2 - 3 } & & ECg A \\
$\angle \mathrm{C}-1^{\prime}-\mathrm{C}-2-\mathrm{C}-3-\mathrm{O}-4$ & $58.4(8)^{\circ}$ & $68.7(6)^{\circ}$ \\
\hline $\mathrm{H}-2-\mathrm{C}-2-\mathrm{C}-3-\mathrm{H}-3$ & $60^{\circ}$ & $68^{\circ}$ \\
\hline
\end{tabular}

(a)

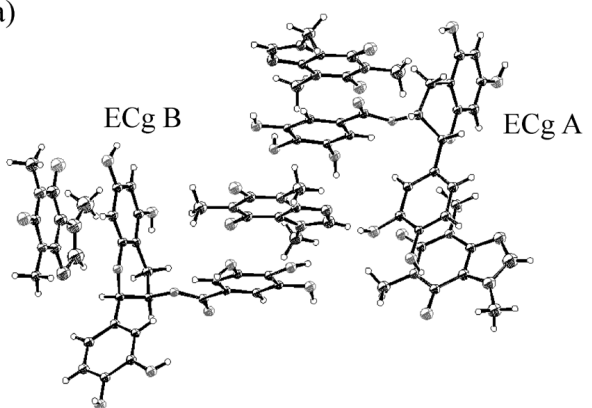

(b)

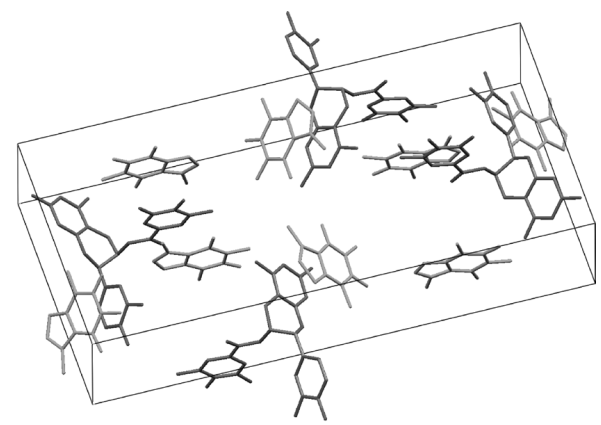

Fig. 5. 2:4 Complex of ECg and Caffeine (a) ORTEP Drawing with Thermal Ellipsoids at 30\% Probability Level (b) One Unit Cell Crystal solvent and hydrogen atoms are omitted for clarity.

and the H-8 proton signal of caffeine in the ${ }^{1} \mathrm{H}-\mathrm{NMR}$ spectrum with 2 protons of the methylene group of DSS as an internal standard.

Preparation of a Crystal of the 1:1 Complex of EC and Caffeine EC $(290.0 \mathrm{mg}, 1.0 \mathrm{mmol})$ and caffeine $(194.0 \mathrm{mg}$, $1.0 \mathrm{mmol})$ were dissolved in distilled water $(300 \mathrm{~mL})$ and the solution was filtered. The resulting filtrate was lyophilized to give a colorless powder. The powder $(30.0 \mathrm{mg})$ was recrystallized from methanol to afford colorless block crystals $(22.4 \mathrm{mg})$, which contained EC and caffeine at a molar ratio of $1: 1$ based on measurement of the integral volume of ${ }^{1} \mathrm{H}-\mathrm{NMR}$ signals. The melting point of the crystal was $160-162^{\circ} \mathrm{C}$.

Preparation of a Crystal of the 2:4 Complex of ECg and Caffeine ECg $\left(10.0 \mathrm{mg}, 2.3 \times 10^{-2} \mathrm{mmol}\right)$ and caffeine $\left(4.4 \mathrm{mg}, 2.3 \times 10^{-2} \mathrm{mmol}\right)$ were dissolved in distilled water $(325 \mu \mathrm{L})$ at $90^{\circ} \mathrm{C}$ and left at room temperature to give a sticky substance $(21.8 \mathrm{mg})$. The sticky substance crystallized slowly over about $3 \mathrm{~d}$ at room temperature to give colorless crystals $(7.4 \mathrm{mg})$, and it was recrystallized from distilled water to give colorless blocks which contained ECg and caffeine at a molar ratio of $1: 2$ based on measurement of the integral volume of ${ }^{1} \mathrm{H}-\mathrm{NMR}$ signals. The melting point of the crystal was $155-157^{\circ} \mathrm{C}$.

X-Ray Crystal Structure Analysis of the 1:1 Complex of EC and Caffeine A crystal of the 1:1 complex of EC and caffeine was determined by X-ray crystallographic analysis at $213 \mathrm{~K}$. X-Ray intensity data of 8547 reflections (of which 3326 were unique) were collected on a Rigaku RAXIS RAPID II imaging plate area detector with graphite monochromated $\mathrm{Cu} K \alpha$ radiation $(\lambda=1.54187 \AA)$. The data were corrected for Lorentz and polarization effects. The structure was solved by direct methods using SIR2004 ${ }^{21)}$ and expanded using Fourier techniques. ${ }^{22)}$ The final cycle of full-matrix least-squares refinement on $F^{2}$ was based on 3326 observed reflections and 335 variable parameters and converged with unweighted and weighted agreement factors of $R=\Sigma|| F_{\mathrm{o}}|-| F_{\mathrm{c}}|/ \Sigma| F_{\mathrm{o}} \mid=0.0699$ $(I>2.00 \sigma(I)), \quad R w=\left[\sum\left(w\left(F_{\mathrm{o}}{ }^{2}-F_{\mathrm{c}}{ }^{2}\right)^{2}\right) / \sum w\left(F_{\mathrm{o}}{ }^{2}\right)^{2}\right]^{1 / 2}=0.1710$. The standard deviation of a unit weight observation was 1.01. Unit

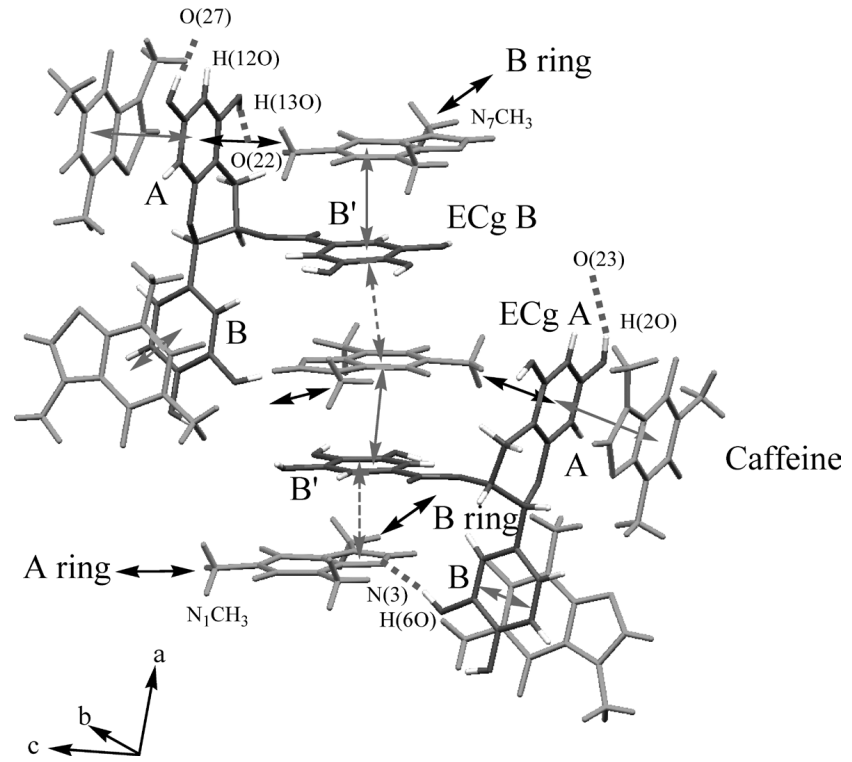

Fig. 6. Layer Structure and Molecular Interactions of 2:4 Complex of ECg and Caffeine

Gray, gray dotted and black both arrows and gray dotted lines indicate face-toface $\pi-\pi$ interactions, offset $\pi-\pi$ interactions, $\mathrm{CH}-\pi$ interactions and hydrogen bonds, respectively.

weights were used. The maximum and minimum peaks on the final difference Fourier map corresponded to 0.32 and $-0.24 \mathrm{e} /$ $\AA^{3}$, respectively. All calculations were performed using the CrystalStructure ${ }^{23,24)}$ crystallographic software package except for refinement, which was performed using SHELXL-97. ${ }^{25)}$ Crystallographic data reported in this manuscript have been deposited with Cambridge Crystallographic Data Center as supplementary publication No. 765712 for $1: 1$ complex of EC and caffeine.

X-Ray Crystal Structure Analysis of the 2:4 Complex of ECg and Caffeine A crystal of the 2:4 complex of ECg and caffeine was determined by X-ray crystallographic analysis at $153 \mathrm{~K}$. X-Ray intensity data of 28046 reflections (of which 
7999 were unique) were collected on a Rigaku RAXIS RAPID II imaging plate area detector with graphite monochromated $\mathrm{Cu} K \alpha$ radiation $(\lambda=1.54187 \AA)$. The data were corrected for Lorentz and polarization effects. The structure was solved by direct methods using SIR2004 ${ }^{21)}$ and expanded using Fourier techniques. $^{22)}$ The final cycle of full-matrix least-squares refinement on $F^{2}$ was based on 7999 observed reflections and 1126 variable parameters and converged with unweighted and weighted agreement factors of $R=\sum \| F_{\mathrm{o}}|-| F_{\mathrm{c}}|| / \Sigma\left|F_{\mathrm{o}}\right|=0.0527$ $(I>2.00 \sigma(I)), \quad R w=\left[\sum\left(w\left(F_{\mathrm{o}}{ }^{2}-F_{\mathrm{c}}{ }^{2}\right)^{2}\right) / \sum w\left(F_{\mathrm{o}}{ }^{2}\right)^{2}\right]^{1 / 2}=0.1454$. The standard deviation of a unit weight observation was 1.05. Unit weights were used. The maximum and minimum peaks on the final difference Fourier map corresponded to 0.87 and $-0.28 \mathrm{e} / \AA^{3}$, respectively. Not all hydrogen atoms of water could be located on the difference electron density maps. All calculations were performed using the CrystalStructure ${ }^{23,24)}$ crystallographic software package except for refinement, which was performed using SHELXL-97. ${ }^{25)}$ Crystallographic data reported in this manuscript have been deposited with Cambridge Crystallographic Data Center as supplementary publication No. 765713 for 2:4 complex of ECg and caffeine.

\section{References}

1) Kuroda Y., Hara Y., "Health Effects of Tea and Its Catechins," Kluwer Academic/Plenum Publishers, New York, 2004.

2) Lambert J. D., Yang C. S., Mutat. Res., 523-524, 201-208 (2003).

3) Ahmad N., Cheng P., Mukhtar H., Biochem. Biophys. Res. Commun., 275, 328-334 (2000).

4) Maeda-Yamamoto M., Kawahara H., Tahara N., Tsuji K., Hara Y., J. Agric. Food Chem., 47, 2350-2354 (1999).

5) Sazuka M., Imazawa H., Shoji Y., Mita T., Hara Y., Isemura M., Biosci. Biotechnol. Biochem., 61, 1504-1506 (1997).

6) Hashimoto F., Ono M., Masuoka C., Ito Y., Sakata Y., Shimizu K., Nonaka G., Nishioka I., Nohara T., Biosci. Biotechnol. Biochem., 67, 396-401 (2003).

7) Kimura M., Umegaki K., Kasuya Y., Sugisawa A., Higuchi M., Eur. J. Clin. Nutr., 56, 1186-1193 (2002).
8) Hayashi N., Ujihara T., J. Org. Chem., 73, 4848-4854 (2008).

9) Okabe S., Suganuma M., Hayashi M., Sueoka E., Komori A., Fujiki H., Jpn. J. Cancer Res., 88, 639-643 (1997).

10) Tezuka M., Suzuki H., Suzuki Y., Hara Y., Okada S., Jpn. J. Toxicol. Environ. Health, 43, 311-315 (1997).

11) Miura S., Watanabe J., Tomita T., Sano M., Tomita I., Biol. Pharm. Bull., 17, 1567-1572 (1994).

12) Hara Y., Watanabe M., Nippon Shokuhin Kogyo Gakkaishi, 36, 951-955 (1989).

13) Seshadri R., Dhanraj N., "Proc. International Flavor Conference, Porto Karras Greece,” pp. 169-180, 1987.

14) Maruyama N., Suzuki Y., Sakata K., Yagi A., Ina K., "Proc. International Symposium Tea Science,” pp. 145-149, 1991.

15) Ishizu T., Sato T., Tsutsumi H., Yamamoto H., Chem. Lett., 39, 607-609 (2010).

16) Davis A. L., Cai Y., Davies A. P., Lewis J. R., Magn. Reson. Chem., 34, 887-890 (1996).

17) Muramatsu K., "Chanokagaku," Asakura Publishing, Tokyo, 1991, p. 124.

18) Karplus M., J. Chem. Phys., 30, 11-15 (1959).

19) Ishizu T., Kajitani S., Tsutsumi H., Sato T., Yamamoto H., Hirata C., Planta Med., 77, 1099-1109 (2011).

20) Cai Y., Gaffney S. H., Lilley T. H., Magnolato D., Martin R., Spencer C. M., Haslam E., J. Chem. Soc., Perkin Trans. 2, 12, 2197-2209 (1990).

21) SIR2004: Burla M. C., Caliandro R., Camalli M., Carrozzini B., Cascarano G. L., Caro L. De, Giacovazzo C., Polidori G., Spagna R., Institute of Crystallography, Bari, Italy, 2005.

22) DIRDIF99: Beurskens P. T., Admiraal G., Beurskens G., Bosman W. P., Gelder R. De, Israel R., Smits J. M. M., The DIRDIF-99 program system, Technical Report of the Crystallography Laboratory, University of Nijmegen, the Netherlands, 1999.

23) CrystalStructure 3.8: Crystal Structure Analysis Package, Rigaku and Rigaku Americas 2000-2007. 9009 New Trails Dr., The Woodlands, TX 77381, U.S.A.

24) CRYSTALS Issue 11: Carruthers J. R., Rollett J. S., Betteridge P. W., Kinna D., Pearce L., Larsen A., Gabe E., Chemical Crystallography Laboratory, Oxford, U.K., 1999.

25) SHELX97: Sheldrick G. M., 1997. 